\title{
The Inscription of Parvomai (Bulgaria)
}

\author{
Reinhardt S. Stein ${ }^{1}$, Giancarlo T. Tomezzoli' \\ ${ }^{1}$ Universiteit Utrecht, Uithof, Holland \\ ${ }^{2}$ European Patent Office, Munich, Germany \\ Email: rstein@uu.nl, gtomezzoli@epo.org
}

Received 27 February 2016; accepted 16 May 2016; published 19 May 2016

Copyright (C) 2016 by authors and Scientific Research Publishing Inc.

This work is licensed under the Creative Commons Attribution International License (CC BY). http://creativecommons.org/licenses/by/4.0/

c) (†) Open Access

\begin{abstract}
A rock inscribed with ancient, strange characters in the locality of Parvomai on the peak Elez, in the area of the villages of Bukovo and Voden near Mount Dragoyna, Northeastern Rodopi region (Bulgaria) was brought to the attention of the archaeologists by Paun Tashev. The inscription attracted our attention and pushed us to exercise our skills for providing its deciphering. The similarities between the name or the words in the inscription with a Slavic god name or surviving words still present in modern Slavic languages indicate, in both the cases, that tribes or peoples speaking Slavic languages were present in Northeastern Rodopi region in the Bronze Age, i.e. well before the VII century A.D. generally accepted period of the arrival of the Slavs in Eastern Europe.
\end{abstract}

\section{Keywords}

Parvomai, Inscription, Deciphering, Thracians, Bulgaria

\section{Introduction}

A rock inscribed with ancient, strange characters in the locality of Parvomai on the peak Elez, in the area of the villages of Bukovo and Voden near Mount Dragoyna, Northeastern Rodopi region (Bulgaria) was brought to the attention of the archaeologists by Paun Tashev. Tashev does not accept to be named the discoverer of the inscription; he simply said "The inscription has been there long before me. I just have saved it for the future generations” (Kmeta.bg., 2016).

"In my native village the memory of inscribed stones is passed from generation to generation. I have seen the inscription 50 years ago. It was by accident. I talked about it on the square of my village and I was from a small interested to know its history. Together with my uncles Ivan and Delcho, we tried to return on the place of the inscribed rock, but we failed to find it because the rock is flat and not erected. At that time I was 18 years old. Probably, all have seen it, but we are simple people and have not taken care of it. Uncles Ivan and Delcho told me that no one has read and understood it, but that, evidently, the inscribed stone was 
very important and I have kept it in mind” (Kmeta.bg., 2016).

Nearly five years ago Tashev met the Bulgarian archaeologist Srebrev. Tashev mentioned the inscribed stone and showed him its pictures. After that they decided to go on the place of the inscribed rock together with Staikov and Konstantinov archaeologists of the Academy of Sciences of Sofia (Kmeta.bg., 2016).

Today, after five years, no dating and deciphering are known. Now time is arrived to provide a dating and a full deciphering of the inscription of Parvomai.

\section{The Inscription of Parvomai}

The rock hosting the inscription of Parvomai is shown in Figure 1 and the layout of the inscription is shown in Figure 2.

At first glance the characters of the inscription resemble the characters of the Linear A, Linear B inscriptions as well as the characters of the older Danubian inscriptions, so that it would be possible to date the inscription to the Bronze Age.

Staikov was the first to try to decipher the inscription on the basis of similarities with hieroglyphs of ancient Egypt (Staikov, 2006). Staikov has reason to seek connection with the country of pyramids, in fact Herodotus and Jordan report the coming Egyptians in Thrace and Egyptian artifacts have been found in Bulgaria. It cannot be denied that some characters of the inscription remind some hieroglyphs and in some case the coincidence is complete.

The approach Staikov's appears to us not convincing, because there are coincidences also between the characters of the inscription and the characters of ancient inscriptions from the cultures of Gradeshnitsa, Karanovo, Tartaria, Vinca, Turdosh, Valchi Dol, well developed in the South Balkan region several millennia BC, and collectively indicated as Danubianstyle or Balkan style scripts (Haarmann, 1989; Merlini 2008; Shan, 1988; Cahill, 2012). Figure 3 summarize said character connections.

The first character of the inscription corresponds perfectly to a character of the inscription on the plate of Gradeshnitsa dated to the $5^{\text {th }}$ millennium BC. The second character corresponds to a character on an artifact from Valchi Dol dated to the $5^{\text {th }}$ millennium BC. This character can be found also among the characters of the Magura cave, which according to some researchers could be dated to the $5^{\text {th }}$ millennium BC. The third character

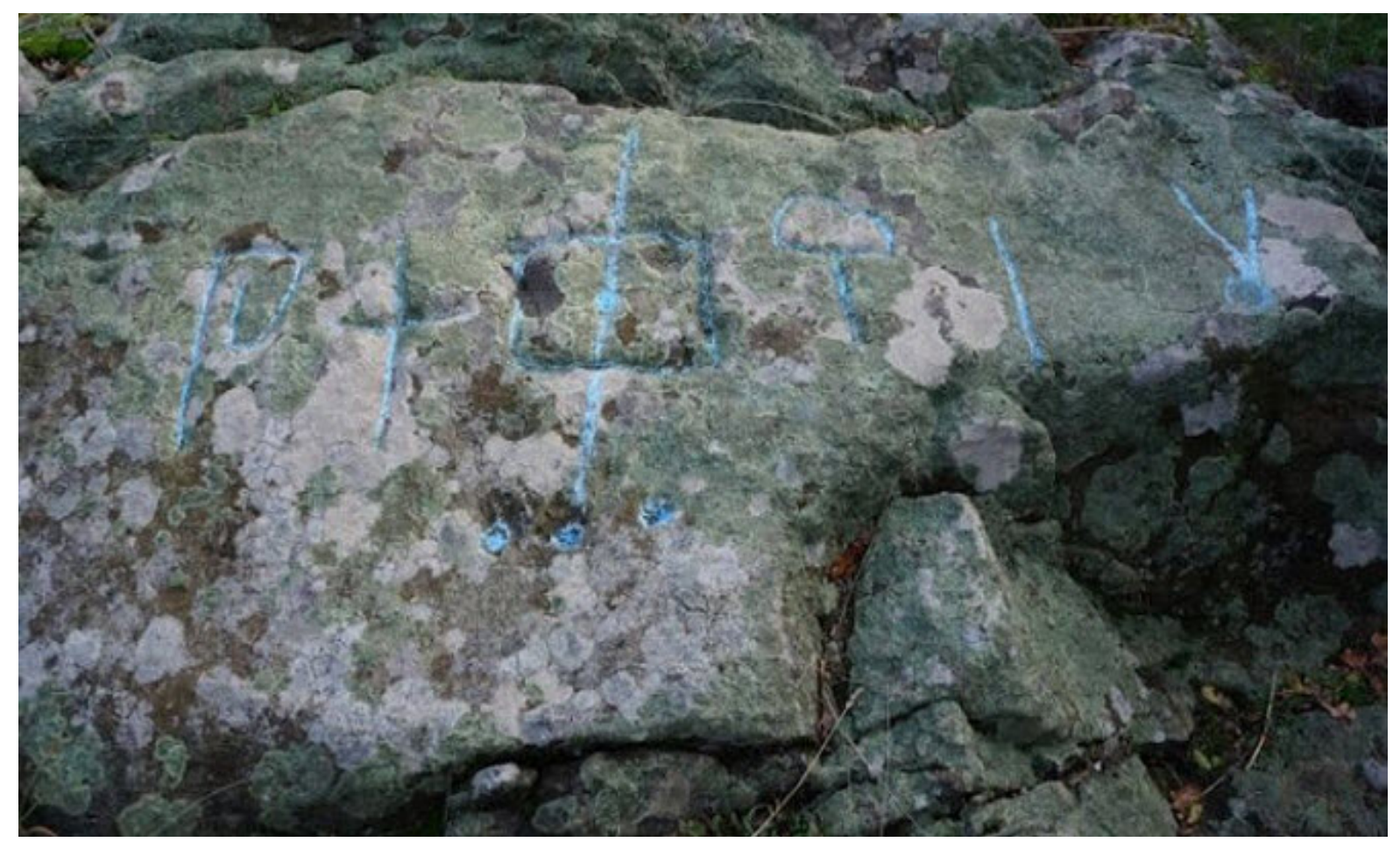

Figure 1. Rock hosting the inscription of Parvomai (Kmeta.bg., 2016). 


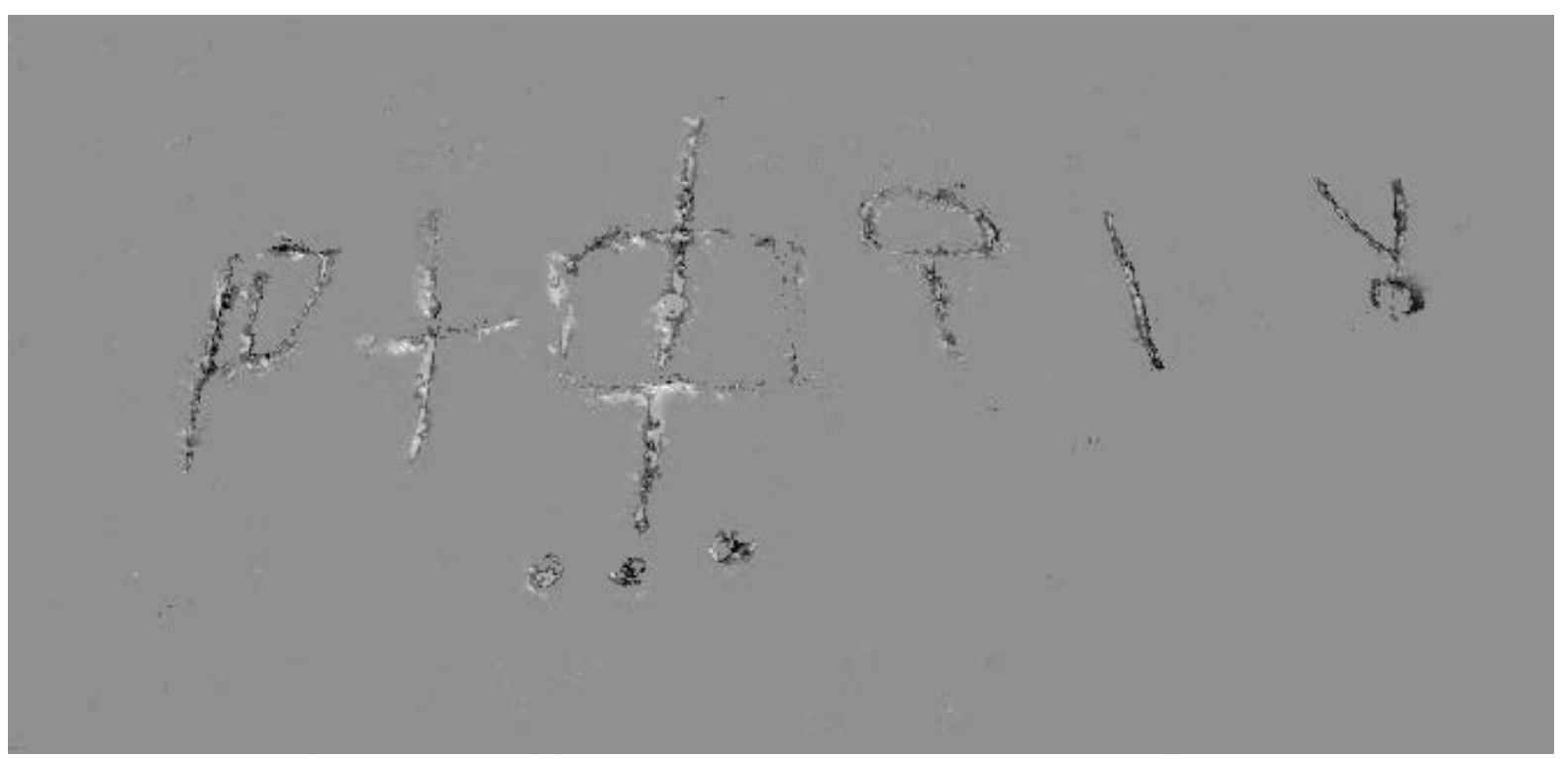

Figure 2. Layout of the inscription of Parvomai.

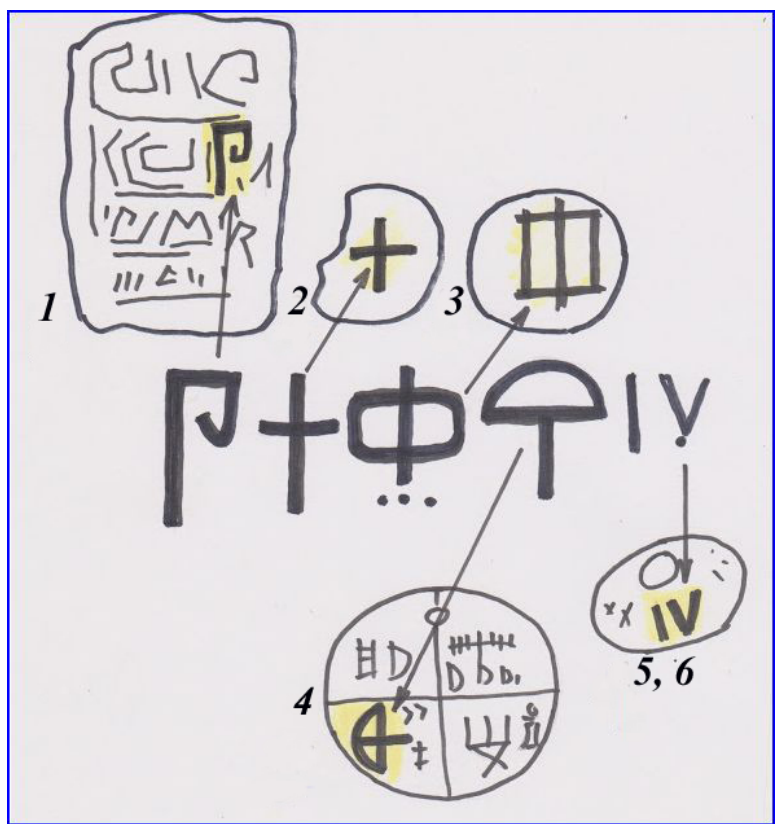

Figure 3. Correspondence between the characters of the inscription of Parvomai with the characters of the inscriptions of: 1 Gradeshnitza, 2 ValchiDol, 3 Vincha ceramics, 4 Tartaria, 5, 6 Turdosh ceramics—emphasis added.

corresponds to the Vincha character registered as OE (Old European) 72. A similar character is known from the Magura cave. The fourth character corresponds to a similar one on the Tartariaplate (Tomezzoli \& Serafimov, 2008) dated to the $5^{\text {th }}$ millennium BC and is registered as OE141. A similar character is known from the Magura cave. The fifth and sixth characters correspond to similar characters on Turdosh ceramics and are registered as OE70 and OE76. Similar character is known from the Magura cave.

Because the characters in the inscription show a stronger resemblance to those of said South Balkan culture than to the characters of the Linear A and Linear B scripts (cf. Figure 4), it is possible formulate the hypothesis that they represent characters of a transitional Balkan script dating from about the early Bronze Age, somewhere in the period 3000 - 2900 BC. The similarities between Linear A and Linear B characters (Evans, 1961; Chadwick, 1995) with those of the cultures of Gradeshnitsa, ValchiDol, Vincha, Magura cave and Tartaria are 


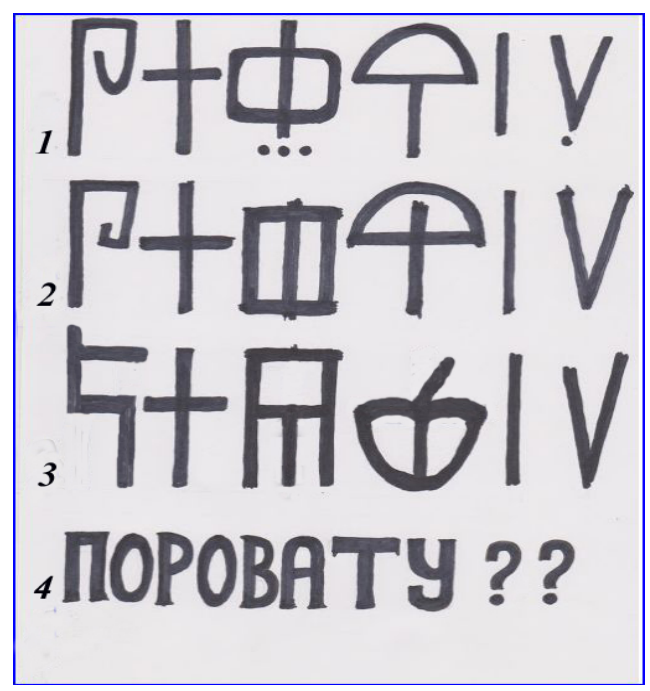

Figure 4. Similarities between the characters of the: 1, Parvomai inscription, 2, Danubianstyle and Balkan style scripts, 3, Linear A and Linear B scripts, 4, sound values of the characters of the Parvomai inscription based on the sound values of the Linear A and Linear B scripts, the sound values of the last two characters remain unknown.

probably due to influences of these South Balkan or Danubian cultures on the Aegean and Mediterranean cultures. This hypothesis is particularly important because it permit to give sound values to the characters in the inscription of Parvomai (Figure 4).

The first character of the Parvomai inscription correspond to the Linear A - B character PO, the second to the Linear A - B character RO, the third to the Linear A - B character VA, the fourth to the Linear A - B character TU. The sound values of the fifth and sixth characters remains for the moment unknown. Therefore, the reading of the inscription of Parvomai could be ПO-PO-BA-TУ-?-? = PO-RO-VA-TU-?-?.

\section{Interpretations of the Inscription}

Although we agree on the reading PO-RO-WA-TU-?-?, our interpretation of its meaning are divergent.

\subsection{Stein's Interpretation}

PO-RO-WA-TU represents the name of the Old Slavic God Porovit worshipped by the Thracians under the names of Porowat or Perkun. Therefore, the inscribed rock probably indicated a place dedicated to the cult of this god, which, as common also in the case of other civilizations, was located on a mount. Perhaps, because of Thracian migrations, the cult of this god spread in Northern Europe at the end of the Bronze Age. A similar term is also present in Pylos Linear B documents PY Fr 1221: po-ro-wi-to, wa-na-se-wi-ja (Palmer, 1963; Foster, 1977; Melena, 1983) and PY Fr 1232 di-pi-si-jo-i, po-ro-wi-to, pa-ko-we (Palmer, 1963; Foster, 1977; Melena, 1983). The characters I V would be a variant of the holyold Bulgarians characters IYI represented also as IVI, present also as iyion the Neolithicpottery from Vinca (Fiedler, 2008).

\subsection{Tomezzoli's Interpretation}

PO-RO-VA-TU means: on the plain;

PO: Slavic prep.: on, over (cf. present Russ., Serb., Bulg. по: on, over);

RO-VA: Slavic subst.: flat (cf. present Russ. Ровно: flat) here in the sense of plain;

TU: Slavic adv.: there (cf. present Russ. Туда; Bulg. Там; Serb. Тамо there);

IV: ? ?

The inscription was therefore an indication for a place on the plain or land near the peak Elez. The characters IV and the three dots under the character WA and the dot under the character V could be further information about the position and the distance to be traveled to reach said place. 


\section{Conclusion}

Although in our different interpretations, now the inscription is open to further study and investigations. The similarities between the name or the words in the inscription with a Slavic god name or surviving words still present in modern Slavic languages indicate, in both the cases, that tribes or peoples speaking Slavic languages were present in Northeastern Rodopi region in the Bronze Age, i.e. well before the VII century A.D. generally accepted period of the arrival of the Slavs in Eastern Europe.

\section{References}

Cahill, M. A. (2012). Paradise Rediscovered. The Roots of Civilization (2 Vol., pp. 813-820). Brisbane: Glass House Books. Chadwick, J. (1995). Linear Band Related Scripts. London: British Museum Press.

Evans, A., \& Myres, J. (1961). Inscriptions in the Minoan Linear script of Class A. In W. C. Brice (Ed.), London: Oxford University Press.

Fiedler, U. (2008). Bulgars in the Lower Danube Region. In F. Curta (Ed.), The Other Europe in the Middle Ages (Vol. 2, pp. 207-209). Leiden-Boston.

Foster, E. D. (1977). Po-ni-ki-jo in the Knossos Tablets Reconsidered, Minos, Vol. 16.

Haarmann, H. (1989). Script from Old Europe to Ancient Crete-A Case of Cultural Continuity. The Journal of Indo-European Studies, 17, 251-276.

Kmeta.bg. (2016).

http://www.kmeta.bg/otkriha-misteriozen-kamenen-nadpis-kraj-p\%D0\%B0rvomaj-snimki-65448.html

Melena, J. L. (1983). Olive Oil and Other Sorts of Oil in the Mycenaean Tablets, Minos vol. 18.

Merlini, M., \& Lazarovici, G. (2008). Settling Discovery, Dating and Utilization of the Tartaria Tablets. In A. S. Luca (Ed.), Acta Terrae Septemcastrensis VII. Proceedings of the International Colloquium: The Carpatian Basin in the Neolitisation of the Balkan Peninsula (pp. 111-196). Sibiu-Romania. http://arheologie.ulbsibiu.ro/publicatii/ats/ats8/acta\%207.pdf

Palmer, L. R. (1963). The Interpretation of Mycenaean Greek Texts. Oxford University Press Monographs Reprints, Oxford University Press.

Shan, M., \& Winn, S. (1988). Pre-Script in Southeast Europe: The Sign System of the Vinča Culture. BAR.

Staikov, J. (2006). http://www.voininatangra.org/modules/ipboard/index.php?showtopic=3916

Tomezzoli, G., \& Serafimov, P. (2008). The Inscriptions of Tartaria. In Skvortsov (Ed.), Pre Cyrillic Slavic Script and Pre Christian Slavic Culture, Materials of the First International Congress (2 Vol.), St. Petersburg, 12-14 May 2008. 